\title{
A Resilience Engineering Approach for Sustainable Safety in Green Construction
}

\author{
Lucio V. Rosa ${ }^{1}$, Josué E. M. França ${ }^{2}$, Assed N. Haddad ${ }^{3}$, Paulo V. R. Carvalho*4 \\ ${ }^{1}$ Estácio de Sá University, Avenida das Américas, 4200, Rio de Janeiro, Brazil \\ e-mail: villavr@poli.ufrj.br \\ ${ }^{2}$ Fluminense Federal University, R. Miguel de Frias 9, Icaraí, Niterói, 24220-900, \\ Rio de Janeiro, Brazil \\ e-mail: josue.maia@poli.ufrj.br \\ ${ }^{3}$ Federal University of Rio de Janeiro, Av. Pedro Calmon 550, Cidade Universitária, 21941-901, \\ Rio de Janeiro, Brazil \\ e-mail: assed@poli.ufri.br \\ ${ }^{4}$ Nuclear Engineering Institute, Cidade Universitária, R. Hélio de Almeida 75, Ilha do Fundão, 21941-614, \\ Rio se Janeiro, Brazil \\ Federal University of Rio de Janeiro, Av. Pedro Calmon 550, Cidade Universitária, 21941-901, \\ Rio de Janeiro, Brazil \\ e-mail: paulov195617@gmail.com
}

Cite as: Rosa, L. V., França, J. E. M., Haddad, A. N., Carvalho, P. V. R., A Resilience Engineering Approach for

Sustainable Safety in Green Construction, J. sustain. dev. energy water environ. syst., 5(4), pp 480-495, 2017 , DOI: http://dx.doi.org/10.13044/j.sdewes.d5.0174

\begin{abstract}
Sustainable construction is a complex endeavour, involving various stakeholders and resulting in situations that are incompletely described or underspecified. Traditional risk assessment methods require a detailed description of the system and safety, focusing on undesirable outcomes, losses, incidents and accidents. Developing this principle, this research describes a new way to deal with risk assessment in the green construction industry using a resilience engineering method based on the functional resonance analysis method and analytic hierarchy process methodologies. The functional resonance analysis method defines a systemic framework to model complex systems based on combinations of function variabilities during normal work. Therefore, to quantify the outcomes for risk assessment, this method was used together with the analytic hierarchy process in a case study during the modernisation work on the Maracanã stadium in Rio de Janeiro. The results of this case study demonstrate that the combined utilisation of the functional resonance analysis method and analytic hierarchy process can be utilised to recognise situations where developments could potentially be without control, which enables this to be used as a basis for performing indicators or a monitoring system. Furthermore, this combined technique can be used to assess and quantify the performance variabilities that may lead to occupational or environmental accidents, and provide new recommendations about how work processes should function, minimising production losses, incidents and accidents.
\end{abstract}

\section{KEYWORDS}

Sustainable construction, Resilience engineering, Functional resonance analysis method, Analytic hierarchy process, Construction safety, Occupational safety, Risk management.

\footnotetext{
* Corresponding author
} 


\section{INTRODUCTION}

Due the economic importance of the construction industry worldwide and its contribution to climate change, there are opportunities to make it more sustainable and minimise the impact on the environment. The focus has centred on three areas: design, construction and use [1]. Special attention should be given to the activities carried out by micro and small sector organisations because they represent the basis of the construction industry for any country, therefore, any innovation that helps to develop aspects of sustainable construction and the environmental impact should be disseminated and applied primarily to the construction industry [2].

While buildings are the largest contributors to environmental degradation [3], they are important to the sustainability of business and, as city dwellers spend $80 \%$ to $90 \%$ of their time indoors [4], they can contribute significantly to the quality of life [5].

In the construction industry, many participants work in an environment under constant change and must deal with different demands [6]. Each work activity has many risk factors and requires systems to ensure quality and safety [7]. It is worth noting that safety issues in the construction industry emerge from the complex characteristics of the work, low educational level of workers, lack of environmental and safety culture and communication problems [8].

The management and coordination of interdependent activities from various companies and workers (contractors, subcontractors, self-employed workers) with diverse work procedures, safety cultures, quality assessment approaches, and so on, increase the variability in work activities as well as the risk of accidents involving people and the environment [9]. In this way, understanding the variabilities and the risks that may arise is extremely important in order to identify the most appropriate risk analysis tools and methodologies for each context [10]. The purpose of risk assessment is to provide evidence-based information and analysis in order to make decisions on how to treat specific risks and how to select the appropriate options [11].

Sustainability and safety are both about resource conservation, sustainable deals with environmental resources and safety with human resources, which should also receive attention in a sustainable environment [12]. To achieve sustainable safety, people should understand how safety is embedded in their daily work activities rather than thinking about safety only after an accident. Occupational and environmental accidents in complex socio-technical systems are more likely to occur when there is a loss of control of work activities [13]. Sustainable safety fulfils the requirement that safety depends on controlling work activities [14].

Conventional explanations for adverse events only see the problems that are inevitable, widespread and inherent in all systems [15]. Therefore, they do not account for small variations that may be combined, resulting in a complete system failure [16]. The methodologies normally used for risk assessment are based on dividing the entire process in isolated tasks that are combined in a linear sequence (e.g. fault tree), which may lead to accidents in a specific environment or operation area. This approach may not capture the actual risk situations experienced in the field. Overall, such methodologies provide a qualitative estimate of risk levels in terms of accident probability (frequency) and consequences (losses). These estimates are based on the professional experience and risk perception of team members in each isolated activity [17]. It does not consider the contribution of eventual interaction among other activities and their risks, especially for those that are not described in the accident analysis or risk model [18].

To overcome this issue, resilience engineering has promoted a new approach for the treatment of dynamic systems in complex environments. In these environments, the daily, routine activities need to be both dynamically stable and flexible rather than rigid. From this paradigm, sustainable safety should not be viewed as an engineering design feature. 
Sustainable safety, rather, must emerge from the joint cognitive human-system functioning [19]. The most important indicator of sustainable safety is the system's ability to adapt to constant environmental changes, with fewer possible risks for the workers and the environment.

To manage sustainable safety from the perspective of resilience engineering, the focus should be on the organisation's adaptive capacity, monitoring work activities and decision-making from the ground floor to management levels, the focus should also be on understanding how the organisation is in fact operating, to see how closely it is functioning in relation to the safety boundary [20]. Thus, managing sustainable safety is concerned with understanding how the system is functioning, how it adapts to different types of disturbances and how it uses the following resilient capacities: buffering capacity, flexibility, margin, tolerance and cross-scale interactions [21].

This research aims to demonstrate an alternative approach to risk assessment that fits the sustainable safety approach in the green construction industry. This approach uses the Functional Resonance Analysis Method (FRAM) together with the Analytic Hierarchy Process (AHP) to conduct risk assessment. FRAM has been developed under the concepts and principles of the resilience engineering, providing a method that analyses the nature of daily work activities, instead of the model of failures. Currently, in the FRAM methodology, analyses related to the identification of performance variability, as well as for the variability aggregation to find potential resonances, are based on the judgment of specialists - a highly subjective evaluation. Thereby, it is completely feasible to use a multi-criteria decision support method for dealing with subjective evaluations in a more adequate way. Among the most widely used of the Multiple Criteria Decision Analysis (MCDA) approaches in the various research domains, the AHP is the one that provides a good compromise between targets, understanding and objectivity.

\section{MATERIALS AND METHODS}

The development and demonstration of how sustainable safety can be applied in the construction industry followed two major research methods: literature reviews and case study. The sustainable construction literature review, the first phase of this research, focused on the practices to construct a building with a highly sustainable performance. The second part of the literature review focused on the methodologies that could be used for risk assessment, considering the premises for sustainability and resilience engineering to achieve a sustainable safety framework. The next stage of the literature review focused on MCDA methodologies aiming at the quantification of considerations (qualitative) and factors (quantitative) within the former subjective FRAM evaluation. Finally, a comprehensive case study demonstrates how risk assessment, according to the sustainable safety framework (FRAM-AHP), can be used in the green construction industry.

\section{Sustainable construction}

Green building is the banner of sustainable development, which has responsibility for the long-term balance involving the economy, environment and health, and thus offers the opportunity to use new concepts in design, thus allowing a reduction in the negative impact of buildings in relation to the environment and society. Green building is a great opportunity not only in terms of mitigating the environmental impact but also in terms of sustainable safety and new ways of risk assessment for the workers, society and economy.

Green building vs. green job. Sustainable development is aimed at environments incorporating continuous improvement in economic and social conditions, including 
environmental issues for future generations [22, 4]. In the construction industry, sustainable development is related to excessive consumption of resources and pollution [23].

Green building means providing a certain specified performance when submitted to a series of requirements [24], while simultaneously minimising disturbances, and developing improvements in the local, regional and global ecosystem from the construction process itself up to the use of the buildings [25]. It also promotes efficiency in the use of resources and adequate operational performance, reducing damages to the environment and risks to human health [26].

There are many ways to implement best practices to minimise the impact on the environment and, therefore, enable a building with high environmental performance [27], providing comfort and hygiene to the users [28]. To this end, the following should be considered: low power consumption for air conditioning and lighting [29], rationalisation of consumption of drinking water [30], use of construction systems and execution of the work to minimise waste generation [31], location of the building to facilitate its access by users without disturbing the neighbourhood, especially during construction [32].

Based on the last 150 years, it can be said that as technology advances, there are disruptions in the economy and careers and disastrous consequences for the environment. Employees must cope with larger systems that control an enormous amount of energy with new sources of danger or increased potential hazards. Fortunately, society can also minimise the impact of technological development as the sustainability framework. In this century, the emergence of so-called green jobs enables a way to determine, from the beginning, if these jobs effectively guarantee an appropriate level of safety and health for workers [33]. Green jobs are those related to the generation of goods, products or services that expand the use of energy from renewable sources, increase energy efficiency, or protect, restore or mitigate damage to the environment [25]. Complementing these concepts, more recent studies have shown that integrated energy systems (hybrid systems) can have a more favourable economic aspect in comparison with single use renewable energy technologies [34]. Hybrid energy systems in buildings can be economically and operationally attractive once they utilise the application of renewable energy technologies by simultaneously ensuring different forms of energy, such as electricity, hot water and heating/cooling capacity, which is a regular demand for building facilities and infrastructure [35].

Green construction in the coming years will certainly gain more and more of the market of traditional construction, but there is not the same certainty with respect to their control on the risks to workers in this emerging market [1]. Green jobs in construction and sectors such as waste management and recycling facilities can be precarious, producing low added value for its benefits, which ultimately requires diverse incentives and financial interventions, so that it can achieve sustainability in the future [25]. Green jobs, to be truly sustainable, must also be sustainably safe for people in the workplace [9]. Understanding the complexity of an occupational risk is crucial to select the most adequate risk assessment tool [5]. Analysing the varied continuous lawsuits in enterprises, universities and research centres, it appears to be possible to determine, since the beginning, that green jobs can ensure an appropriate level of safety and health for people in the workplace [36].

\section{Risk assessment in complex systems}

The correct choice of an accident analysis and risk assessment model can be key to a successful strategy of occupational and environmental accident prevention in any industrial sector [37]. Conventional risk analysis methods utilised in industry are based on sequencing and linearisation of tasks like Hazard and Operability (HazOp) analysis and Fault Tree Analysis (FTA). These methods were elaborated more than 50 years ago, 
and the attempt to include human and organisational factors still has problems when used for risk analysis of complex socio-technical systems [15].

Resilience engineering. Traditional models of accident and risk assessment are based on chains of events and usually do not consider the combination of possible variations in human actions, equipment behaviour or the relations embedded in socio-technical systems [38]. Traditional models consider the chain of events in a static way from a postulated design basis. An accident or accident evolution are represented as a sequence of well-defined events, in which one or more triggering events (main cause) combine in a static way, leading to well-defined effects [39].

Sustainable safety problems can result from various combinations of causes, ranging from industry to industry, making them suitable for the different methods and tools for assessing risk. These tools and methodologies can be qualitative, semi-quantitative or quantitative. Some of that can deal with human reliability analysis [37]. Several risk factors including organisational structure, safety culture, communication, clear instructions, training, standards and norms, responsibility and leadership are already proven as influential for safety in many work settings [40, 41].

Resilience is the ability of a system to adjust its functioning (shift of processes, strategies and coordination), even when variability in its functioning is unexpected and causes disruption in the regular capacities and adaptations [42]. In fact, resilience concerns the ability to recognise and adapt to unanticipated perturbations that call the model of competence into question [43, 21].

Resilience engineering is a new vision for safety management in socio-technical systems. Rather than looking for the causes of an accident, the aim of these new concepts is to recognise how systems work to develop increased resilient systems, i.e., instead of having systems that are not aware of unsafe variabilities, they operate in higher risk levels, or create safety management systems to identify variabilities to drive and help in providing adequate answers before the accident occurs [15].

Resilience engineering makes the following assumptions [43]:

- The performance conditions are always under-specified, leading to individuals and organisations to systematically adjust their behaviour to match the conditions in force and to meet the new resource limits. To the extent that time and resources are finite, such adjustments are inevitably approximate;

- Not all adverse events can be attributed to a failure or a malfunction of components or system functions. Some events can be understood as the result of unexpected combination of performance variability within system;

- Safety management should be based on everyday work activities, and not solely on events that had already occurred;

- Safety should not be addressed in isolation from other management functions of organisations, because safety and productivity have an interdependent relationship. Safety must, therefore, be obtained from improvements and not restrictions.

For the system or organisation to be resilient, four key systemic capabilities must be met, i.e., the ability to [43]:

- Deal with expected and unexpected variations and threats in a robust and flexible way;

- Monitor what is really happening in the entire system;

- Anticipate risks and opportunities;

- Learn from previous experiences.

Resilience engineering seeks to understand the entire process, without focusing on specific faults, because complex systems usually fail in complex ways. The safety 
processes contribute to safety when they are viewed according to the other objectives of the company, including environmental and operational efficiency [44].

The adoption of the conceptual basis of resilience engineering does not mean the abandonment of existing practices, but a different perspective for using these methodologies, and at the same time, the definition of the requirements for the adoption of new methodologies [43].

The identification of risks in work settings is an important foundation for the success of risk management, nevertheless, in construction industry projects, is very difficult to identify the risk level of the entire set of processes [5]. The construction industry is characterised by underspecified work activities, continuous changes, use of various resources, transitory occupation, and an unhealthy work environment. The construction industry has diverse and elaborate work activities where several partners are present. The work is done under constant changes by the various demands and each activity has many specific items of risk and safety factors [8]. Some issues hamper the identification of risks such as knowledge and information, and multiplicity and lack of standardisation of procedures.

To deal with the problems of current risk assessment tools, many researchers have developed new methods [45-48]. One of these methods is the FRAM, which is established in resilience engineering, providing an empirical approach that aims to describe and analyse emerging fault in complex socio-technical systems [43, 49].

Functional Resonance Analysis Method (FRAM). The sustainable safety of a system can be characterised as an emergent property, that is, it is something that cannot be designed like the component parts of the system [40]. In this sense, the occupational and environmental accidents can be characterised as emergent properties of complex systems [50]. Virtually all risk assessments are conducted in a state of relative ignorance about the full operation of the system in question, and in some cases in a state of complete ignorance regarding its typical functioning [51]. FRAM is structured on the following basic principles of resilience engineering [51]:

- Failures and successes are equivalent insofar as they have the same origin;

- Everyday work is always underspecified and adjusted to suit the conditions;

- Performance variability of one specific function is rarely sufficient to produce an accident, rather, accidents are viewed as a non-linear effect coming from a combination of multiple function variability;

- The variability of some functions can resonate - or propagate via strong coupling and enhance each other - resulting in an unexpected increase in the variability of the whole system whose consequences may be accidents (that are not cause and effect chains).

FRAM is applied according to the following steps [43]:

- Identify system functions describing their objectives and inputs, outputs, preconditions, resources, time and control;

- Characterise each function variability - observed and potential - according to the five criteria of analyses: input, prerequisites, supplies, period and control through two options (timing and precision);

- Combine the functions as they appear in daily work, including potential adjustments and adaptations;

- Define functional resonances, taking into account the potential and actual link among functions;

- Afford ways to verify and decrease unwanted variability and resonance.

FRAM enables the representation of normal performance variability within the socio-technical system, describing the interaction among the functions [40]. The main functions may be composed of interactions among human operators, among human 
operators and technical systems, among human operators and resources needed in emergency response, and so forth [43]. In this study, to minimise the subjectivity associated with the qualitative analyses of the functions performed by experts' judgments required by FRAM, a multi-criteria decision support method was added.

Multi-criteria decision support methods. The information and comprehension needed to analyse and evaluate complex socio-technical functions involving work activities is frequently featured as intricate, not precise, uncertain and fuzzy [40]. Designed or structured methods to assist decisions and analyses may reduce mismatches caused by subjective evaluations [52]. In these terms, decision-making is a process composed of four parts: intelligence, design, choice and review [53, 54].

Multi-criteria decision support methods are used in scenarios where there are numerous and perhaps conflicting goals, several decision-makers and a concomitant handling of complex matters [55]. AHP is one of the most widely used methods for these analyses in several research domains, enabling treatment for complex situations and problems, assisting decision-makers in scenarios of high risk, complexity and uncertainty [56-58]. AHP structures the decision process, fine-tuning the decision-making procedures, respecting the preferences of the user with overall consistency by setting a global uniformity ratio $[59,60]$.

The default Saaty 1-9 scale used in this work is based on psychological observations. AHP methodology is to evaluate quantitative as well as qualitative criteria and alternatives on the same preference scale. The decision maker does not need to supply a numerical judgment, instead a relative verbal evaluation is enough. AHP methodology predicts a consistency test in order to extract meaningful priorities [57].

The AHP model is supported by three basic principles [61]:

- Structuring the hierarchy - This principle involves identifying the overall objective (focus), the criteria that must be satisfied to fulfil the focus, sub-criteria under each criterion and the alternatives;

- Establishing priorities - The first step is to make pairwise comparisons to specify the decision-makers' preferences using the Saaty fundamental scale, to compare pairs of like elements in each level of a hierarchy against a criterion in the next higher level. The second step is to synthesise the judgments made in the pairwise comparisons to obtain the relative priorities of each element. Finally, the average is calculated over the rows by adding the values in each row of the normalised matrix and then dividing the rows by the number of entries in each;

- Measuring the logical consistency - The AHP measures the overall consistency of judgments by means of a Consistency Ratio (CR). The value of CR should be $10 \%$ or less to be acceptable.

The Saaty fundamental scale, to establish priorities, is an AHP fundamental scale for pairwise comparisons used in the first step of this methodology. This scale is the combination of a verbal scale and numerical scale, where each word of the verbal scale has a corresponding number of the numerical scale:

- "same" stands for number 1 ;

- "slight" stands for number 3;

- "little" stands for number 5;

- "a lot" stand for number 7;

- "extremely" stands for number 9 .

The intermediate levels are defined as numbers 2, 4, 6 and 8 .

\section{Case study}

The utilisation of FRAM-AHP in green construction was done during the modernisation of Maracanã stadium in Rio de Janeiro, which involved the Leadership in 
Energy and Environmental Design (LEED) certification procedures. A detailed explanation of this case study was done in [62]. Two groups of construction workers participated in the FRAM-AHP modelling/assessment. One group was formed by three Health, Safety and Environment (HSE) specialists, to deal with questions related to the overall process, and three workers' representatives, to deal with questions related to the specific work activities. These workers were part of the team responsible for the reuse and recycling of waste generated by the construction, mainly involving the use of the crusher machine. The chosen process is a typical sustainable process that handles the construction waste produced on site differently, taking the demolished concrete and transforming it to a base construction material by using the crusher machine, as shown in Figure 1. The main steps of this recycling process are:

- Waste selection at the construction site;

- Inserting the waste into the crusher machine;

- Crushing the waste in the crusher machine;

- Delivering the crushed waste (base material) by trucks.

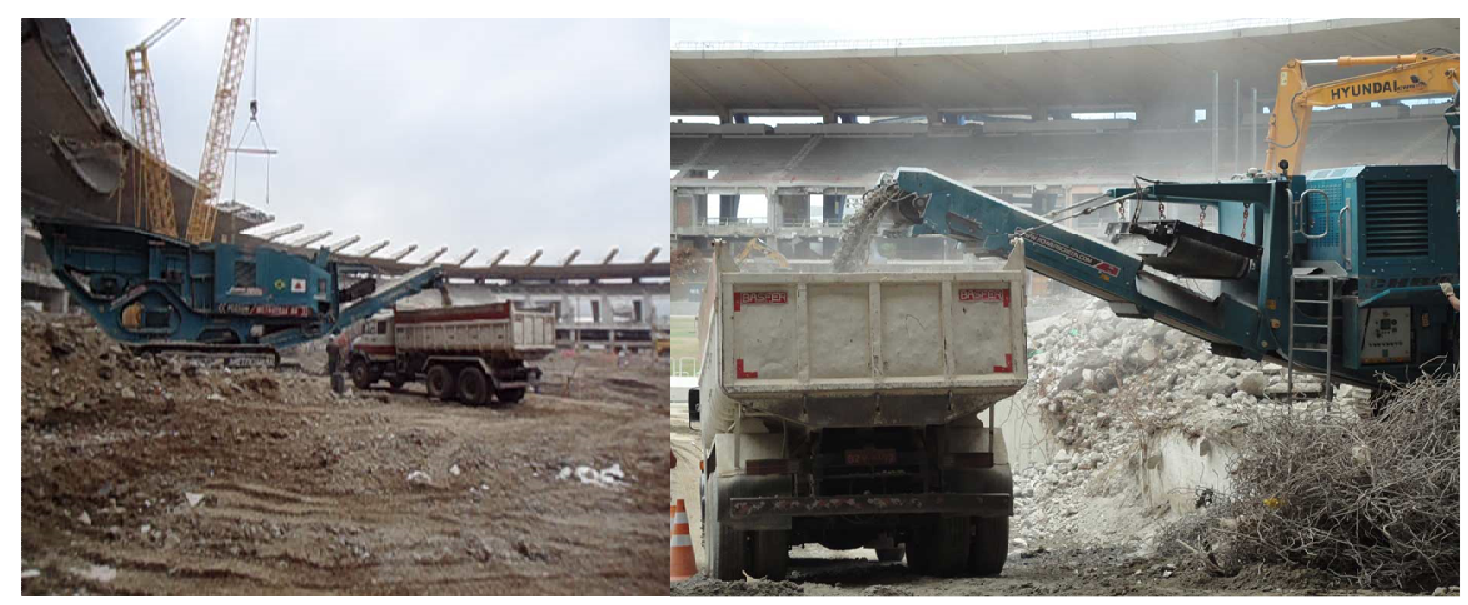

Figure 1 . The recycling process of the construction waste on site, done by a crusher machine

FRAM-AHP risk assessment. A crucial step is to recognise the main roles and related functions of the process to construct the FRAM model. Twenty foreground and background functions (organisational functions that influence the work activities) have been identified. The most important foreground functions modelled were material selection, receiving the material, initial checklist, operation without load, operation under load, levelling control, material delivery and control of the finished product. To characterise the potential variations in the function outputs, there are expressions of variability in function outputs that are based on categories that describe how the variability can be seen, from the output or from the effects [43]. The AHP was used to quantify the output variabilities of each function based on experts' and/or workers' judgments.

The hierarchical structure of AHP created for the actual or potential variability of the FRAM functions is shown in Figure 2. It is based on five criteria that characterise FRAM functions - entrance, preconditions, resources, time and control, related to four options: force/distance/direction, timing/duration, sequence and wrong object. Focus groups and interviews were used with workers and managers to develop and validate some written questions (questionnaire) based on the AHP methodology.

Every trial stage with the AHP should be done by evaluators who have thorough knowledge of the topic under study. Due to the singular characteristics of the activities and tasks, the judgments were done only by the team of workers' representatives, formed by two operators and one work supervisor. 


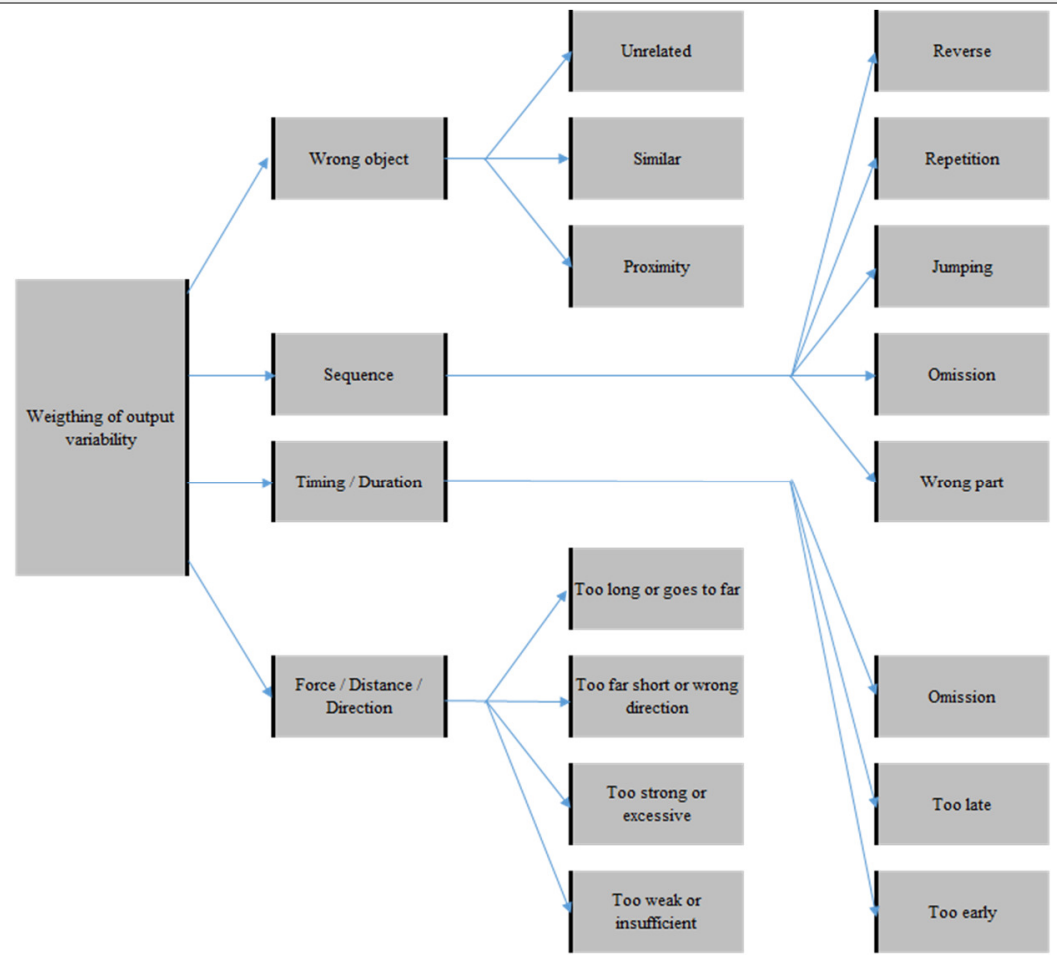

Figure 2. Hierarchical structure of AHP to identify variabilities (potential or actual)

The following phase was the analysis and recognition of functional links, also supported by AHP methodology, applying the hierarchical structure that characterises variability aggregation presented in Figure 3. It should be noted that these structures used the same five criteria of the previous evaluation of the functions. In the same way as in the previous step, focus groups and interviews were used to collect value judgments that were consolidated by a questionnaire built according to AHP structure and methodology. Due to the specific characteristics of the activities and tasks of this process, the judgments of functional resonances were done solely by the team of experts in the overall work process. Functional resonance analysis helps to identify possible uncontrolled variation areas in the segments of the system that should be controlled to prevent accidents. It is worth noting that uncontrolled situations or functional resonance links (large variability situations) are established per the vectors of priorities related to output variability of each function, linked with vectors of priorities related with the upstream-downstream functions coupling under the same criteria. The final step of the method - supplying ways to verify and decrease variability - considers procedures necessary to manage the risk placed by the occurrence of uncontrolled situations (damping functional resonance).

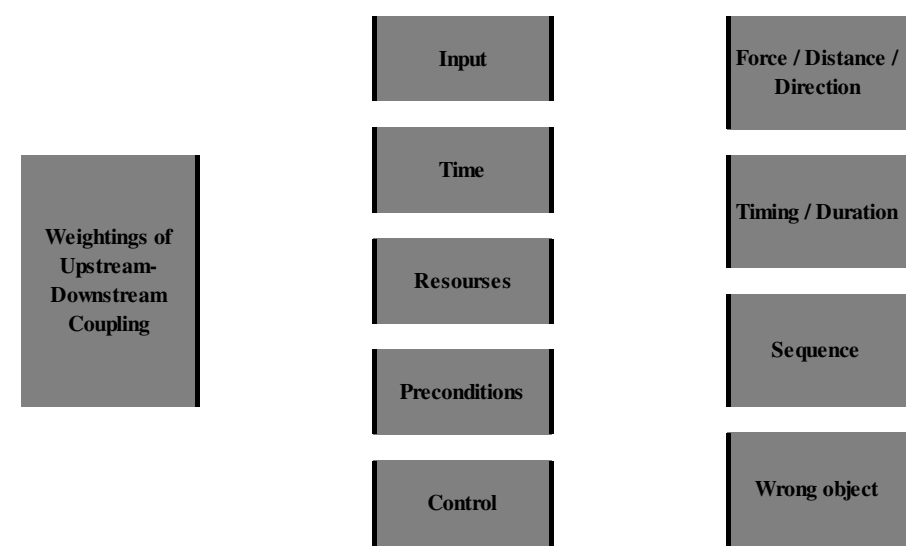

Figure 3. Hierarchical structure of AHP to identify aggregation of variability 


\section{RESULTS AND DISCUSSION}

The function characterisation of variabilities (actual and potential) was done exclusively by the team of workers' representatives, as shown in Table 1 . The functions operations under load, control of finished product, material selection and levelling control have a relatively high variation in the output (wrong object $-\mathrm{O}$ ).

Table 1. Weighting of output variability [62]

\begin{tabular}{c|ccccc}
\hline \multicolumn{7}{|c}{ Vectors of priorities (weight of variability - output) } \\
\hline Functions/criteria & $\begin{array}{c}\text { Sequence } \\
(\mathrm{S})\end{array}$ & $\begin{array}{c}\text { Force, } \\
\text { distance and } \\
\text { direction }(\mathrm{F})\end{array}$ & $\begin{array}{c}\text { Timing and } \\
\text { duration } \\
(\mathrm{T})\end{array}$ & $\begin{array}{c}\text { Wrong object } \\
(\mathrm{O})\end{array}$ & $\begin{array}{c}\text { Consistency } \\
\text { ratio }\end{array}$ \\
\hline $\begin{array}{c}\text { Initial checklist } \\
\text { Operation }\end{array}$ & 0.431 & 0.038 & 0.1 & 0.431 & 0.094 \\
$\begin{array}{c}\text { without load } \\
\text { Operation }\end{array}$ & 0.218 & 0.043 & 0.65 & 0.089 & 0.082 \\
$\quad$ under load & 0.044 & 0.142 & 0.142 & 0.672 & 0.09 \\
$\begin{array}{c}\text { Control of the } \\
\text { finished product }\end{array}$ & 0.097 & 0.044 & 0.227 & 0.632 & 0.077 \\
Material selection & 0.054 & 0.054 & 0.306 & 0.586 & 0.034 \\
Material delivery & 0.062 & 0.438 & 0.438 & 0.062 & 0 \\
Receive material & 0.058 & 0.672 & 0.212 & 0.058 & 0.091 \\
Levelling control & 0.053 & 0.053 & 0.269 & 0.625 & 0.09 \\
\hline
\end{tabular}

The characterisation of functional couplings done only by the team of professional experts is seen by the relative importance of the various aspects involved: ( $\mathrm{S}$ ) for sequence, $(\mathrm{F})$ for force, distance and direction, $(\mathrm{T})$ for timing and duration and $(\mathrm{O})$ for wrong object (Table 2). Furthermore, the functions are connected according to the model in Figure 4. As shown in Table 2, many functions have high variability in the input. Additionally, operation with no load and levelling control show high variability in preconditions (0.57), and operation under load has problems in its control (0.428).

Table 2. Weightings of upstream-downstream coupling

\begin{tabular}{|c|c|c|c|c|c|c|}
\hline & & & Vectors o & priorities & & \\
\hline & & Upstrea & n-downstre & n coupling wei & hts & \\
\hline Functions/criteria & Input & Time & Resources & Preconditions & Control & $\begin{array}{c}\text { Consistency } \\
\text { ratio }\end{array}$ \\
\hline $\begin{array}{c}\text { Operation with } \\
\text { no load }\end{array}$ & 0.051 & 0.051 & 0.051 & 0.57 & 0.277 & 0.053 \\
\hline $\begin{array}{l}\text { Operation } \\
\text { under load }\end{array}$ & 0.428 & 0.048 & 0.048 & 0.048 & 0.428 & 0 \\
\hline $\begin{array}{l}\text { Control of the } \\
\text { product (finished) }\end{array}$ & 0.634 & 0.111 & 0.111 & 0.057 & 0.087 & 0.036 \\
\hline Material delivery & 0.639 & 0.061 & 0.061 & 0.181 & 0.058 & 0.036 \\
\hline Receive material & 0.586 & 0.05 & 0.05 & 0.264 & 0.05 & 0.086 \\
\hline Levelling control & 0.03 & 0.162 & 0.149 & 0.51 & 0.149 & 0.046 \\
\hline
\end{tabular}


The determination of possible functional resonances, i.e., the most important sources for variability that may produce undesired outcomes, is based on the potential couplings among functions. Vectors of priorities related with output variability linked with the vectors of priorities of the upstream-downstream coupling show the priority functional resonance links, as indicated in red in Figure 4. It shows the relevant significance of the output variance against functional links (FRAM-AHP).

The red links in Figure 4 indicate the connections where there are more variation possibilities in the couplings due to high values in the function output and in one of the downstream function entrances. For instance, the red link among output of initial checklist and levelling control precondition is because the initial checklist function has an output with relatively high levels in sequence $(S=0.431)$ and wrong object $(\mathrm{O}=0.431)$, levelling control upstream-downstream has also a relatively high value (0.51). Therefore, the numbers obtained with the FRAM-AHP help in the final evaluation of possible variabilities in the function couplings, otherwise, this entire evaluation would be made according to the feelings of the expert responsible for the analysis.

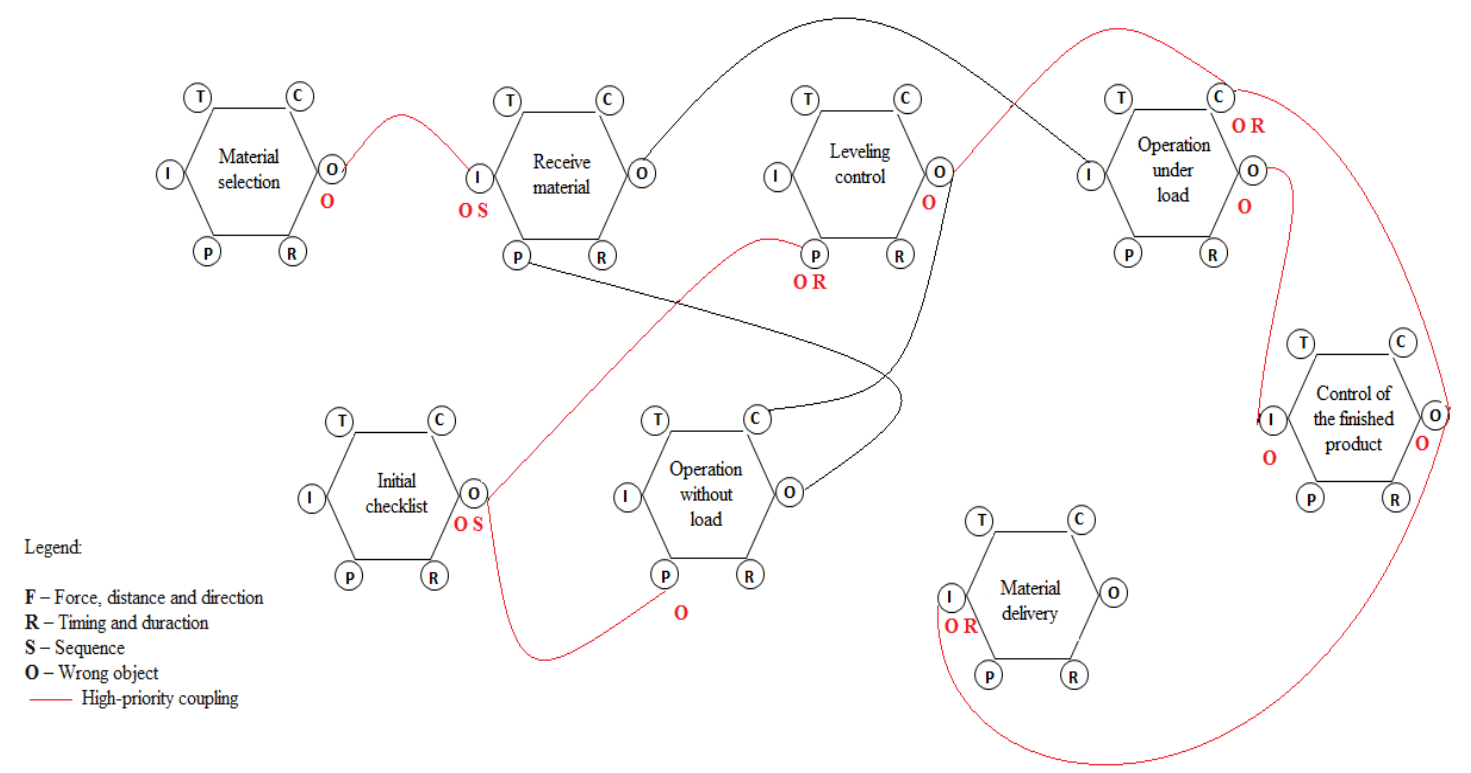

Figure 4. Functional model with critical or high priority function couplings in red

From this model, the team responsible for the analysis found that the effectiveness of the entire system demands the correct levelling of the equipment involved in the operations. As shown in Tables 2 and 3 and Figure 4, levelling control has high variability in preconditions (timing and wrong object), which reflects in its output. Variability in the level control output causes difficulties for the control of the function 'Operation under load'. This means that if levelling shows high variation during operations, loading and unloading is going to happen in highly variable conditions, without proper control, leading to a scenario of possible loss of control - a clear safety issue for work accidents. It is also important to notice that adequate levelling of the equipment reduces consumption of energy, the level of noise, the spread of pollutants and provides adequate productivity of the process. Therefore 'levelling' should be viewed as the most important issue to achieve sustainable safety.

\section{CONCLUSIONS}

As work in the construction industry is done by more than one company, the responsibility for some aspects of the operation is usually that of a team with members from various companies. In this sense, the combination of aspects that can generate a 
disproportionate impact is further accentuated because decisions can be taken separately for each aspect, not considering the relationship with other features and aspects.

The main goal of this study was to propose a framework for sustainable safety, investigating the risks and dangers associated with the sustainable construction industry, using concepts and methods of resilience engineering. The findings indicate that FRAM could support the identification of functional performance variability, which can generate a positive or negative impact for environmental and occupational safety, generating recommendations at the design level and thereby ensuring a greater effectiveness of environmental and occupational safety management strategies.

With the use of FRAM methodology, which is structured on the principles of resilience engineering, it was determined that it pays to invest in performance variability management as it allows better monitoring and mitigating of the variability that can lead to undesired outcomes. Moreover, it allows taking actions to anticipate, monitor and enforce the variability that can lead to positive results or successes, i.e., the ones that should be encouraged.

The use of AHP with FRAM in risk assessments allowed the exploration of new perspectives for risk assessment, encouraging the involvement of several stakeholders and quantifying some results. It is worth highlighting that the use of AHP also served as the basis for the necessary collaboration among the analysis team as well as present in a clear way the most likely and important scenarios.

The FRAM-AHP studies enabled the concomitant involvement of various experts, including workers, in different phases of evaluation, and decreased the characteristic subjectivity of risk analysis methodologies performed in complex sociotechnical scenarios.

FRAM-AHP modelling, as presented in this study, can be used to recognise situations where developments could potentially be without control, which enables this to be used as a basis for performing indicators or monitoring system. The initial checklist role goals ensure the suitable working of the elements of the most important equipment (identification of variabilities), FRAM-AHP can be utilised to enhance the performance monitoring index, bonded with capacitation issues, technical instruction and certification for workers involved in the operations.

A better understanding of overall process functioning and couplings with other processes enables a better understanding of related safety issues by managers and workers, in the different levels of technical and human interaction involved in the processes, providing ways to make safety sustainable throughout the construction period.

\section{ACKNOWLEDGEMENT}

Paulo Carvalho acknowledges the grants from Conselho Nacional de Pesquisas (CNPq) and Fundação de Amparo a Pesquisa do Rio de Janeiro (FAPERJ) that were partially used in this research.

\section{REFERENCES}

1. Bibbiy, A., Green Jobs in Construction: Small Changes, Great Effect (in Spanish), Trabajo, La Revista de La OIT, No. 70, pp 38-41, 2010.

2. Bohari, A., Skimore, M., Xia, B., Teo, M., Zhang, X. and Adham, K., The Path towards greening the Malaysian Construction Industry, Renewable and Sustainable Energy Reviews, Vol. 52, pp 1742-1748, 2015, https://doi.org/10.1016/j.rser.2015.07.148

3. Lu, W. and Yuan, H., Investigating Waste Reduction Potential in the Upstream Processes of Offshore Prefabrication Construction, Renewable and Sustainable Energy Reviews, Vol. 28, pp 804-811, 2013, https://doi.org/10.1016/j.rser.2013.08.048 
4. Menassa, C. C., Evaluating Sustainable Retrofits in Existing Buildings under Uncertainty, Energy and Buildings, Vol. 43, No. 12, pp 3576-3583, 2011, https://doi.org/10.1016/j.enbuild.2011.09.030

5. Tan, Y., Ochoa, J., Langston, C. and Shen, L., An Empirical Study on the Relationship between Sustainability Performance and Business Competitiveness of International Construction Contractors, Journal of Cleaner Production, Vol. 93, pp 273-278, 2015, https://doi.org/10.1016/j.jclepro.2015.01.034

6. Chen, P., Ong, C. and Hsu, S., The Linkages between Internationalization and Environmental Strategies of Multinational Construction Firms, Journal of Cleaner Production, Vol. 116, pp 207-216, 2016, https://doi.org/10.1016/j.jclepro.2015.12.105

7. Mehta, R. and Agnew, M., Analysis of Individual and Occupational Risk Factors on Task Performance and Biomechanical demands for Simulated drilling Task, International Journal of Industrial Ergonomics, Vol. 40, No. 5, pp 584-591, 2010, https://doi.org/10.1016/j.ergon.2010.06.003

8. Pinto, A., Nunes, I. and Ribeiro, L., Occupational Risk assessment in Construction Industry: Overview and Reflection, Safety Science, Vol. 49, No. 5, pp 616-624, 2011, https://doi.org/10.1016/j.ssci.2011.01.003

9. Zhao, X., Hwang, B. and Gao, Y., A Fuzzy Synthetic Evaluation approach for Risk assessment: A Case of Singapore's Green Projects, Journal of Cleaner Production, Vol. 115, pp 203-213, 2016, https://doi.org/10.1016/j.jclepro.2015.11.042

10. Fung, I., Tam, V., Lo, T. and Lu, L., Developing a Risk assessment Model for Construction Safety, International Journal of Project Management, Vol. 28, No. 6, pp 593-600, 2010, https://doi.org/10.1016/j.ijproman.2009.09.006

11. ISO/IEC, International Organization for Standardization/International Electrotechnical Commission, ISO/IEC 31.010:2009, Risk Management - Risk Assessment Techniques, 2009.

12. Zuo, J., Zillante, G., Wilson, L., Davidson, K. and Pullen, S., Sustainability Policy of Construction Contractors: A Review, Renewable and Sustainable Energy Reviews, Vol. 16, No. 6, pp 3910-3916, 2012, https://doi.org/10.1016/j.rser.2012.03.011

13. Rasmussen, J., Risk management in a Dynamic Society: A modelling Problem, Safety Science, Vol. 27, No. 2-3, pp 183-213, 1997, https://doi.org/10.1016/S0925-7535(97)00052-0

14. Taubitz, M., How Safety fits with Sustainability, Occupational Health \& Safety Magazine, 2010, https://ohsonline.com/Articles/2010/09/01/How-Safety-Fits-withSustainability.aspx, [Accessed: 24-June-2012]

15. Carvalho, P., The use of Functional Resonance Analysis Method (FRAM) in a Mid-air Collision to understand some Characteristics of the Air Traffic management System, Reliability Engineering and System Safety, Vol. 96, No. 11, pp 1482-1498, 2011, https://doi.org/10.1016/j.ress.2011.05.009

16. Shiralia, G., Motamedzadeb, M., Mohammadfama, I., Ebrahimipourc, V. and Moghimbeigid, A., Challenges in building Resilience Engineering (RE) and Adaptive Capacity: A Field Study in a Chemical Plant, Process Safety and Environmental Protection, Vol. 90, No. 2, pp 83-90, 2012, https://doi.org/10.1016/j.psep.2011.08.003

17. Harms-Ringdahl, L., Safety Analysis - Principles and Practice in Occupational Safety $\left(2^{\text {nd }}\right.$ ed.), Taylor and Francis, London, UK, 2001, https://doi.org/10.4324/9780203302736

18. Nieto-Morote, A. and Ruz-Vila, F., A Fuzzy approach to construction Project Risk assessment, International Journal of Project Management, Vol. 29, No. 2, pp 220-231, 2009, https://doi.org/10.1016/j.ijproman.2010.02.002

19. Mitropoulos, P. and Namboodiri, M., New Method for measuring the Safety Risk of Construction Activities: Task demand assessment, Journal of Construction Engineering and Management, Vol. 137, No. 1, pp 30-38, 2011, https://doi.org/10.1061/(ASCE)CO.1943-7862.0000246 
20. Iñigo, E. A. and Albareda, L., Understanding Sustainable Innovation as a Complex Adaptive System: A Systemic approach to the Firm, Journal of Cleaner Production, Vol. 126, pp 1-20, 2016, https://doi.org/10.1016/j.jclepro.2016.03.036

21. Woods, D., Essential Characteristics of Resilience (Hollnagel, E., Woods, D., Leveson, N., eds.), Resilience Engineering: Concepts and Precepts ( $\left.1^{\text {st }} \mathrm{ed}.\right)$, Ashgate, Aldershot, UK, 2006.

22. Ding, G. K. C., Sustainable Construction - The Role Environmental assessment Tools, Journal of Environmental Management, Vol. 86, No. 3, 451-464, 2008, https://doi.org/10.1016/j.jenvman.2006.12.025

23. Ortiz, O., Castells, F. and Sonnemann, G., Sustainability in the Construction Industry: A Review of recent developments based on LCA, Construction and Building Materials, Vol. 23, No. 1, pp 28-39, 2009, https://doi.org/10.1016/j.conbuildmat.2007.11.012

24. ASTM, American Society for Testing and Materials, E 2114-01 - Standard Terminology for Sustainability Relative to the Performance of Buildings, ASTM International, 2011.

25. Chen, H., Green and Healthy Jobs, University of California at Berkeley, 2010, http://www.elcosh.org/record/document/2076/d001091.pdf,

[Accessed: 13-March-2013]

26. Zuo, J. and Zhao, Z., Green building Research-current Status and Future Agenda: A Review, Renewable and Sustainable Energy Reviews, Vol. 30, pp 271-281, 2014, https://doi.org/10.1016/j.rser.2013.10.021

27. Lu, W. and Tam, V., Construction Waste management Policies and their Effectiveness in Hong Kong: A Longitudinal Review, Renewable and Sustainable Energy Reviews, Vol. 23, pp 214-23, 2013, https://doi.org/10.1016/j.rser.2013.03.007

28. Haapio, A. and Viitaniemi, P., A Critical Review of building Environmental assessment Tools, Environmental Impact Assessment Review, Vol. 28, No. 7, pp 469-482, 2008, https://doi.org/10.1016/j.eiar.2008.01.002

29. Zhang, X., Shen, L. and Zhang, L., Life Cycle assessment of the Air Emissions during building Construction Process: A Case Study in Hong Kong, Renewable and Sustainable Energy Reviews, Vol. 17, pp 160-169, 2013, https://doi.org/10.1016/j.rser.2012.09.024

30. Ruparathna, R. and Hewage, K., Sustainable procurement in the Canadian Construction Industry: Current Practices, Drivers and Opportunities, Journal of Cleaner Production, Vol. 109, pp 305-314, 2015, https://doi.org/10.1016/j.jclepro.2015.07.007

31. Dahlbo, H., Bachér, J., Lähtinen, K., Jouttijärvi, T., Suoheimo, P., Mattila, T., Sironen, S., Myllymaa, T. and Saramäki, K., Construction and Demolition Waste management - A Holistic Evaluation of Environmental Performance, Journal of Cleaner Production, Vol. 107, pp 333-341, 2015, https://doi.org/10.1016/j.jclepro.2015.02.073

32. Pietrosemoli, L. and Monroy, C., The Impact of Sustainable Construction and Knowledge management on Sustainability Goals, A Review of the Venezuelan Renewable Energy Sector, Renewable and Sustainable Energy Reviews, Vol. 27, pp 683-691, 2013, https://doi.org/10.1016/j.rser.2013.07.056

33. Zhao, D., He, B., Johnson, C. and Mou, B., Social Problems of Green buildings: From the Humanistic needs to Social Acceptance, Renewable and Sustainable Energy Reviews, Vol. 51, pp 1594-1609, 2015, https://doi.org/10.1016/j.rser.2015.07.072

34. Nizetic, S., Duic, N., Papadopulos, A. M., Tina, G. M. and Grubisic-Cabo, F., Energy Efficiency Evaluation of a Hybrid Energy System for building Applications in a Mediterranean Climate and its Feasibility Aspect, Energy, Vol. 90, Part 1, pp 1171-1179, 2015, https://doi.org/10.1016/j.energy.2015.06.053

35. Nizetic, S., Tolj, I. and Papadopulos, A. M., Hybrid Energy Fuel Cell based System for Household Applications, Energy Conversion and Management, Vol. 105, pp 1037-1045, 2015, https://doi.org/10.1016/j.enconman.2015.08.063 
36. Rajendran, S., Gambatese, J. A. and Behm, M. G., Impact of Green building design and Construction on Worker Safety and Health, Journal of Construction Engineering and Management, Vol. 135, No. 10, pp 1058-1066, 2009, https://doi.org/10.1061/(ASCE)0733-9364(2009)135:10(1058)

37. Badri, A., Nadeau, S. and Gbodossou A., Proposal of a Risk-factor-based Analytical approach for integrating Occupational Health and Safety into Project Risk Evaluation, Accident Analysis and Prevention, Vol. 48, pp 223-234, 2012, https://doi.org/10.1016/j.aap.2011.05.009

38. Levenson, N., A New Accident Model for Engineering Safer Systems, Safety Science, Vol. 42, No. 4, pp 237-270, 2004, https://doi.org/10.1016/S0925-7535(03)00047-X

39. Pereira, R., Morgado, C., Luquetti dos Santos, I. and Victor, P., Safety analysis of the Deepwater Horizon Blowout based on the Functional Resonance analysis Model (FRAM), Proceedings of the $5^{\text {th }}$ International Conference on Applied Human Factors and Ergonomics - AHFE, pp 327-337, Kraków, Poland, July 19-23, 2014.

40. Grecco, C., Vidal, M., Cosenza, C., Luquetti dos Santos, I. and Carvalho, P., Safety Culture assessment: A Fuzzy Model for improving Safety Performance in a Radioactive Installation, Progress in Nuclear Energy, Vol. 70, pp 71-83, 2014, https://doi.org/10.1016/j.pnucene.2013.08.001

41. Ismail, Z., Doostdar, S. and Harun, Z., Factors influencing the implementation of a Safety management System for Construction Sites, Safety Science, Vol. 50, No. 3, pp 418-423, 2012, https://doi.org/10.1016/j.ssci.2011.10.001

42. Steen, R. and Aven, T., A Risk Perspective Suitable for Resilience Engineering, Safety Science, Vol. 49, No. 2, pp 292-297, 2011, https://doi.org/10.1016/j.ssci.2010.09.003

43. Hollnagel, E., FRAM - The Functional Resonance Analysis Methods: Modeling Complex Socio-technical Systems (1 ${ }^{\text {st }}$ ed.), Ashgate, Aldershot, UK, 2012.

44. Carvalho, P., Gomes, J., Huber, J. and Vidal, M., Normal People working in Normal Organizations with Normal Equipment: System Safety and Cognition in a Mid-air Collision, Appl. Ergon., Vol. 40, No. 3, pp 325-340, 2009, https://doi.org/10.1016/j.apergo.2008.11.013

45. Aneziris, O., Topali, N. and Papazoglou, I., Occupational Risk of building Construction, Reliability Engineering and System Safety, Vol. 105, 36-46, 2012, https://doi.org/10.1016/j.ress.2011.11.003

46. Ayoub, N., Musharavati, F., Pokharel, S. and Gabbar, H. A., Risk based Life Cycle assessment Conceptual Framework for Energy Supply Systems in Large Buildings, Journal of Cleaner Production, Vol. 107, pp 291-309, 2015, https://doi.org/10.1016/j.jclepro.2015.04.075

47. Gurcanli, G. and Mungen, U., An Occupational Safety Risk analysis Method at Construction Sites using Fuzzy Sets, International Journal of Industrial Ergonomics, Vol. 39, No. 2, pp 371-387, 2009, https://doi.org/10.1016/j.ergon.2008.10.006

48. Sovacool, B. K, Andersen, R., Sorensen, S., Sorensen, K., Tienda, V., Vainorius, A., Schirach, O. M. and Bjørn-Thygesen, F., Balancing Safety with Sustainability: Assessing the Risk of Accidents for Modern Low-carbon Energy Systems, Journal of Cleaner Production, Vol. 112, Part 5, pp 3952-3965, 2016, https://doi.org/10.1016/j.jclepro.2015.07.059

49. Aguilera, M., Fonseca, B., Ferris, T., Vidal, M. and Carvalho, P., Modelling Performance Variabilities in Oil Spill Response to improve System Resilience, Journal of Loss Prevention in the Process Industries, Vol. 41, pp 18-30, 2016, https://doi.org/10.1016/j.jlp.2016.02.018

50. Dekker, S., Cilliers, P. and Hofmeyr, J., The Complexity of Failure: Implications of Complexity Theory for Safety Investigations, Safety Science, Vol. 49, No. 6, pp 939-945, 2011, https://doi.org/10.1016/j.ssci.2011.01.008

51. Hollnagel, E., Barriers and Accident Prevention ( ${ }^{\text {st }}$ ed.), Ashgate, Aldershot, UK, 2004. 
52. Saurin, T. and Carim Junior, G., Evaluation and improvement of a Method for assessing HSMS from the Resilience Engineering Perspective: A Case Study of an Electricity Distributor, Safety Science, Vol. 49, No. 2, pp 355-368, 2011, https://doi.org/10.1016/j.ssci.2010.09.017

53. Costa, H., Multicriteria Decision Aid - AHP (in Portugese) ( ${ }^{\text {st }}$ ed.), Abepro, Rio de Janeiro, Brasil, 2006.

54. Parra-Lopez, C., Calatravra, J. and Haro-Gimenez, T., A Multi-criteria Evaluation of the Environmental Performances of Conventional, Organic and Integrated Olive-growing Systems in the South of Spain based on Experts' Knowledge, Renewable Agriculture and Food Systems, Vol. 22, No. 3, pp 189-203, 2007, https://doi.org/10.1017/S1742170507001731

55. Gomes, L., Araya, M. and Carignano, C., Decision-making in Complex Scenarios: Introduction to Discrete Methods of Multicriteria Decision (in Portugese), Pioneira, São Paulo, Brasil, 2004.

56. Ali, H. and Nsairat, S., Developing a Green building assessment Tool for developing Countries: Case of Jordan, Building and Environment, Vol. 44, No. 5, pp 1053-1064, 2008, https://doi.org/10.1016/j.buildenv.2008.07.015

57. Saaty, T., The Analytic Hierarchy Process: Planning, Priority Setting, Resource Allocation ( $1^{\text {st }}$ ed.), McGraw-Hill, New York, USA, 1980.

58. Tiwari, D., Loof, R. and Paudyal, G., Environmental-economic decision-making in Lowland irrigated Agriculture using Multi-criteria analysis Techniques, Agricultural $\begin{array}{llllll}\text { Systems, } & \text { Vol. } & 60, \quad \text { No. } & 2, & \text { pp }\end{array}$ https://doi.org/10.1016/S0308-521X(99)00021-9

59. Kaya, I. and Kahraman, C., A Comparison of Fuzzy Multicriteria Decision making Methods for Intelligent building assessment, Journal of Civil Engineering and Management, Vol. 20, No. 1, pp 59-69, 2014, https://doi.org/10.3846/13923730.2013.801906

60. Saaty, T., How to make a Decision: The Analytic Hierarchy Process, European Journal of Operational Research, Vol. 48, No. 1, pp 9-26, 1990, https://doi.org/10.1016/0377-2217(90)90057-I

61. Saaty, T., Decision making for Leaders: The Analytic Hierarchy Process for Decision in a Complex World ( $1^{\text {st }}$ ed.), RWS Publications, Pittsburgh, USA, 1999.

62. Rosa, L. V., Haddad, A. N. and Carvalho, P. V. R., Assessing Risk in Sustainable Construction using the Functional Resonance Analysis Method (FRAM), Cogn., Tech. \& Work, Vol. 17, No. 4, pp 559-573, 2015, https://doi.org/10.1007/s10111-015-0337-z 